Cracking Open Co-Creation: Categories, Stories, and Value Tension in a Collaborative Design Process

Peter Lloyd

University of Brighton, UK

p.a.1loyd@brighton.ac.uk

Arlene Oak

University of Alberta, Canada

aoak@ualberta.ca

\begin{abstract}
In this paper we show how stories and categories help to frame and express values in a car accessory design process. We consider how a group of designers plan two co-creation workshops through categorising participants in ways that impact upon the subsequent process of design. We then describe how two stories emerge during the design process, additionally structuring design discussion through linking 'past particulars' - experiences and behaviours that the co-creation process reveals - with 'imagined particulars' - stories that place specific actors, objects and relations into an imagined context. We propose a key function of stories within this collaborative design process as holding value tension, allowing contrasting values to coexist together.
\end{abstract}

Highlights

- The role of stories in framing collaborative design practice

- The management of contrasting categories and values through discourse

- How stories represent 'value tension' in design processes

- The performance of design as the negotiation of value tension

Keywords:

Collaborative design, Framing, Communication, Design Process, Storytelling

The recent resurgence of interest in the concept of framing as a way of both analysing and thinking about the design process has usefully focused our attention on structures that anchor 
the flow of discourse in design processes (Paton \& Dorst 2011, Umney, Lloyd \& Potter 2014, Dorst 2015, Jornet \& Roth 2017, Dong \& Macdonald 2017). Rather than looking in detail at specifically cognitive elements of understanding, as did the first Design Thinking Research Symposium (DTRS) common-data study (Cross, Dorst \& Christiaans 1996), framing aligns more readily with social and constructivist ways of looking at design behavior, and comes closer to how design professionals conduct and describe their own activity. In effect, frames serve to structure practices of design, and also how objects, including people, are perceived within those practices (Ensink \& Sauer 2003, Umney \& Lloyd 2018).

Related to the concept of framing is that of storytelling (Lloyd 2000, McClosky 1996), since frames are at least partially expressed through the co-construction of verbal stories (Goffman 1981). Storytelling and narratives are widely studied in relation to creative practice (Beckman \& Barry 2009, Oak 2013b) as well as "how people actually use stories in everyday, mundane situations" (Bamberg \& Georgakopoulou 2008). In our view, storytelling is a more effective analytical orientation to work with as it implies a time-based operational logic; a sequence of actions by actors that make sense through a narrative arc being created or told. Our recent studies have looked at the interleaving of narrative in the presentation and performance of design (Lloyd \& Oak 2016, Oak 2013b) that has allowed us to explore aspects of expertise, authority, and gender through critical analyses of the narrative voice telling the story.

The data that we use in this paper came from the eleventh in the series of Design Thinking Research Symposia (Ball, Christensen \& Halskov 2017) and provided us with an opportunity to develop the concept of storytelling as it occurs in collaborative design and co-creative practice. The DTRS11 dataset featured a series of eighteen collaborative design sessions of (mainly) Scandinavian designers preparing and then analysing two day-long co-creation workshops that took place with potential Chinese consumers. The workshops were held in China with the aim of developing new product ideas for the emerging luxury automobile accessories market. Collaborative design sessions took place both in Scandinavia and China, and two background interviews before and after the design process, provided context for looking at the data. The dataset thus provides a unique window into the current corporate design world and the practices labeled as 'collaborative design', 'design thinking' and 'cocreation'. Figure 1 shows a timeline for the 22 session of the dataset and design process. Sessions 2-5, 7-12, and 14-21 featured the designers in real-time video. Sessions 6 and 13 featured Chinese participants and were presented partly in time-lapse video and without 
transcripts. Interviews in sessions 1 and 22 were audio only. Sessions varied in length between 10 minutes $(6,13)$ and 100 minutes $(5)$ with an average time of 47 minutes, and total time of 17 hours, 20 minutes. The design process itself could be summed up as the design of three different things: workshops, stories, and car accessories.

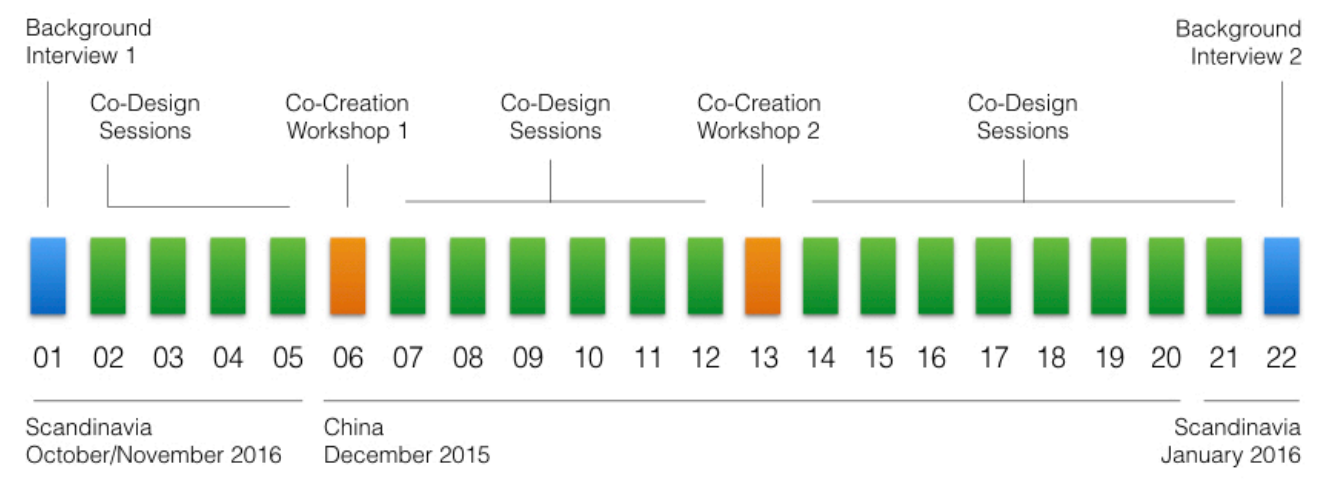

Figure 1. Timeline for the DTRS11 dataset and design process.

At the beginning of Session 1 Ewan, the chief designer and main protagonist in the dataset, sets down his intention for the co-design process to: 'basically crack open co-creation in general and then maybe calibrate our expectations' (Line 5). Likewise this paper seeks to critically examine aspects of the co-creation process by first, considering the selection of participants in the co-creation workshops along with the construction of contrasting values that results. We then look at a number of ideas around the concept of story, storytelling, and narrative as they apply in the dataset before focusing in detail on two particular stories that emerge: 'sexy commitment' (which is also considered elsewhere by Dong \& Macdonald $\left.(2017)^{1}\right)$ and 'Mercedes guy'. The paper's main contribution is to outline how, in terms of expertise in design thinking, stories can help to frame, express and negotiate what we term value tension: conversational narratives that enable participants in design to simultaneously present opposing values without the need to resolve them.

\section{Approaches to Analysis}

Rather than concentrating on specific sessions of the data, the paper takes a number of seams through the dataset and draws on analytic orientations that centre on the analysis of narrative in discourse and language. While we avoided strongly theorised perspectives or defined hypotheses when we first approached the data, we were sensitised to certain issues by 
familiarity with, for example, the analytic tool of Membership Categorisation Analysis (Sacks 1972, Housley \& Fitzgerald 2002, Stokoe 2012). This approach has been used to study how, within spoken accounts and justifications, people are categorised by, for example, gender, age, and social class in ways that are also associated with positive or negative evaluations. From the outset we were attentive to how participants in design might categorise and evaluate persons, places, products and situations.

Our orientation was broadly ethnographic and similar to previous work where we have looked at television programmes of the design process (Lloyd \& Oak 2016). In that work, and here, we watched the entire dataset of audio-visual recordings, noting both regularities and idiosyncracies of participant performances. We regularly discussed what we thought was going on in the recordings, seeking structures in the data where we had a sense that specific discourses were being enacted. We then looked for further corroboration and evidence as we developed our understanding of what was being presented before then thinking through the mechanisms that would help to explain what we observed. Our aim was to gain familiarity with what was going on in ways that appeared to be meaningful or significant to the participants themselves.

\section{Considering and Categorising the Co-Creation Participants}

The design team's attention to potential consumers, and their recognition that the participants in the workshops must be thoughtfully selected and managed, makes up a considerable portion of the interaction that is recorded in the early phases of the dataset. For example, in Session 3, the members of the design team discuss their individual perceptions and experiences of previous co-design activities and think of various ways of including participants. The participants are a group of potential consumers of the products being designed and have been invited to the co-creation sessions to work in groups with the designers. In the illustrative comments below the design team consisting of Kenny, Nina, Abby and Ewan (along with the DTRS11 representative, David) work together to plan the cocreation workshops:

$14 \mathrm{~K}$ I think we're gonna do some really good preparations here, but in the end, when we're sitting there with the people, then we really need to calibrate it against them... 


$$
\begin{aligned}
& {[\ldots]} \\
& 32 \mathrm{~N} \text { (We need tools to use) with the people, so we can get the information we } \\
& \text { need, but not in the direct way, like we cannot be asking them, like what do } \\
& \text { you want and stuff like that, we need to really make them play the role... } \\
& {[\ldots]} \\
& 45 \text { E We're setting the scene, it's very artificial, super artificial ... but, then again, I } \\
& \text { think that is my analogy very often, to say "okay, imagine these people are } \\
& \text { your friends, and you're doing something awesome together"... } \\
& {[\ldots]} \\
& \text { 56: A The communication is going to be really really interesting to see what kind of } \\
& \text { input we get, what stories will actually impact them and kind of set their } \\
& \text { emotions on fire... }
\end{aligned}
$$

Throughout Session 3 the team actively set the scene in which the participants, who are strangers to each other, will interact. The designers discuss in some detail the possible use of prompts and tools to make them feel more at ease during the two co-creation workshops. The team's sensitivity to the local social organisation is further indicated by their in-depth discussions of how to manage the workshop participants' self-and-other perceptions so that successful interaction can occur. The issue of how the workshop participants might view themselves and each other, in ways that could impact upon the communicative competencies of individuals and thereby influence the success of the workshop arises at the beginning of Session 3. Here, the team discuss a large number of 'screening' factors for the participants, concentrating particularly on how to create balanced and egalitarian conditions that deemphasise notions of social hierarchy and encourage free communication within the group. In effect, by imagining how to have particular participants involved in particular ways, the design team are helping to frame the future narrative that could unfold from the meeting, and frame subsequent design activities.

For example, the design team talk about seeking people who are "not too high up the societal ranks in terms of hierarchy" (Line 24), "average people, no one too high up in the society" (Line 81). Additionally, Ewan suggests that the users "need to be premium car users", but that they should also "be at the same level" (Line 82) with "some kind of alignment or common ground" (Kenny, Line 120) so that they are able to communicate effectively. The design team talks about how best to create this cohesion by, for instance, limiting the age range of participants or including participants from the same family to increase the likelihood that participants will be comfortable speaking with one another. The team then discusses whether 
they should be concerned to balance participant characteristics such as introversion and extroversion, levels of creativity, senses of humour, degrees of independence, and desire to actively participate in the workshop. Additionally, the design team consider requiring a dress code, Abby says: "we could also kind of say to them 'okay, everyone needs to wear black' or white or something so that they don't differentiate themselves too much with fashion" (Line 228).

In their concern for managing the membership categories of participants' social class, age, kinship relations, and appearance (and also their concern to manage the participants' experience of the group meetings themselves) the design team construct stories about who is most relevant to include in the process of design. The terms they use for the future participants help to frame what will happen in the workshops, with the designers shaping these events by managing the social organisation and the potential psychological and emotional effects they may have on those who are involved. The designers are thus setting a scene and imagining the kind of actors who will perform for them. Their attention to group dynamics can also be seen in Session 4 where, for example, the designers recognise that, upon meeting at the workshop, participants may automatically self-select to place themselves into orderly social categories, such as hierarchies performed through naming occupations (e.g. 'CEO', 'housewife'), or by attention to dress and appearance. To disrupt such participantbased category affiliations and assumptions, and to create an alternative order, the design team discuss having the workshops begin with each participant choosing two images of animals as personal avatars. These animals will then be joined together and each participant will explain to the others how the hybrid creature represents them and the particular values they wish to be aligned with. By choosing, combining, and then presenting animals as categorisations of identity, the design team are framing the workshop as a particular experience of group order and cohesiveness: one that mimics the design team's 'flat hierarchy' (Background Interview 1, Line 11), as it builds on social equality and informality, rather than on income difference and public decorum.

The framing of the selection process or 'screener' (Session 1, Line 24) activities, for participants taking part, carries with it a set of underlying, relatively egalitarian values that the designers of the co-creation sessions wish to represent in the workshops, indeed values that arguably do not reflect contemporary, urban Chinese culture more generally but are instead more deliberately reflective of their own, Scandinavian cultural roots. For example, a cultural 
orientation to egalitarian discussion is seen early in Session 1, where Ewan exhorts his fellow designers to work towards 'cracking open co-creation'. Ewan asks the group to "go one by one and just spend half a minute to talk about what we think [the co-creation workshop] should be" (Line 5). Ewan seeks a brief narrative from everyone as he provides an opportunity for each designer to use their past experiences of workshops as stories that can inform the future co-creation workshop for THE COMPANY.

Creating egalitarian conditions under which the workshop participants will be comfortable enough to share their experiences is clearly an important aim of the designers and can be seen as an expression of participatory and user-centred approaches to design. Although the role of power within apparently collaborative processes has been questioned, the explicit aims of many co-designers are to encourage and empower consumers (Prahalad \& Ramaswamy 2004, Sanders \& Stappers 2008). The collaborative nature of the co-creative practices in the DTRS11 data also accord with Scandinavian design's underlying expectation that its designers and products should 'care' for their users in ways that align with, if only unevenly, political and cultural values of social responsibility" (Murphy 2015). The social and cultural values of 'care' and equality thus form part of the everyday 'norms-in-action' (Housley \& Fitzgerald 2009) performed by the design team as they work to choose and categorise particular participants as well as create the particular workshop activities that will help to frame the subsequent analysis and design process.

\section{The Design Narrator and the Use of Stories}

Although there are several designers involved in the DTRS11 data, it is Ewan who presents most prominently in almost all sessions. He performs a number of functions but as chief designer, he is essentially the person who controls the process as it unfolds and who comments most consistently on both how the process is going and the value of other contributions. Ewan's role as the narrator and assessor is enhanced by him being the only person featured in the contextualising interviews before and after the main sessions of data. In these interviews Ewan describes the context and outcomes of the overall design project in a kind of 'once upon a time - happy ever after' temporal structure (Booker 2004). Since he is given the opportunity to narrate the overarching story from his point of view, Ewan is thus placed in a position of authority by the editors of the DTRS11 dataset (when compared to other project stakeholders such as Hans or Tiffany, who work for THE COMPANY and who 
have some authority over the success or otherwise of Ewan's team). Ewan himself is clearly aware of the importance of creating and narrating 'stories' within design practice, as he explicitly references 'stories' and 'storytelling' throughout the dataset - effectively recognising his role as both part of the story and the narrator of it. (In this sense he somewhat resembles the TV presenter Kevin McCloud who in the popular UK series Grand Designs can be seen as reinforcing an individual heroic account of the design process (Lloyd \& Oak, 2016)).

As well as articulating the need to create stories, Ewan is himself someone who selfconsciously uses stories (in combination with analogies and metaphors) to communicate his thoughts to others. In Session 9, a story he tells takes on a moral disposition in a widerranging discussion about the idea of 'commitment', a concept that came up in the first CoCreation Workshop (CC1, Session 6). Commitment is not something that can be purchased by consumers, Ewan suggests with his story, but something that needs an opportunity to develop. The story Ewan tells to frame his perception of commitment derives from a parable from the Bible about courage: which is this guy who asks for courage. He prays to God "can I get courage?" and he never gets the courage, he never gets courage at all. And then [he speaks to] a wise man [who says:] "what do you think? do you think God would just give you courage, or do you think he will give you the opportunity to be courageous?" I think that's what we need to do here, the opportunity to take commitment, instead of just giving them the free stuff. They need an opportunity to be courageous so they can shine through that in a way...

The structure of this story hinges around a re-framing of how to become virtuous (in the case of the story, how to have courage). By using a story to suggest that you don't simply become virtuous by fiat, either through being given virtue or by purchasing it, but by being given an opportunity to develop virtue, Ewan is skilfully making a link to how a product, i.e. a car accessory, can represent an opportunity to consumers. The story thus bridges two perceptions of value (as product or as opportunity) while keeping their inter-relationship clear. The reasoning is rhetorical and suggestive, rather than being logical and conclusive but it is the 
way that the story enables a translation of the singular value of courage to a polarity between product and opportunity that should be noted.

\section{Story Finding and Construction}

A particularly salient story that the group both search for and create in order to frame others' understanding of the products being developed is what is referred to by them as a 'regionrelevant story', i.e. a cultural and location-relevant narrative that will underpin the designrelated interpretations and decisions of both the designers and the potential consumers of the car accessories. The explicit topic of the 'region-relevant story' continues through the 20 sessions of the DTRS11 data. Figure 2 shows a graph of the occurrences of words related to 'story' (e.g. 'stories', 'storytelling', etc.) for each session, including the two interviews with Ewan. In total there are 176 mentions of the two words although most mentions (105) occur subsequent to the second Co-Creation Workshop (CC2), which suggests that this was a search that became more focused towards the end of the design process. Notable, however, is Session 9, with 18 mentions, and that appears to be the point at which the team develops consensus around the importance of having a 'story', perhaps at Ewan's direction, since it is he who mentions the word 'story' 12 times (67\% of all mentions). Clearly, the designers are conscious of narrative in helping to frame their own, and workshop participants', understandings of what could emerge from the co-creation workshops, To explore how the need for a 'region-relevant story' begins to be shaped by the designers, Session 9 provides an example of a phrase that emerges as an underpinning shorthand term for an important and recurring reference story: 'sexy commitment'. 


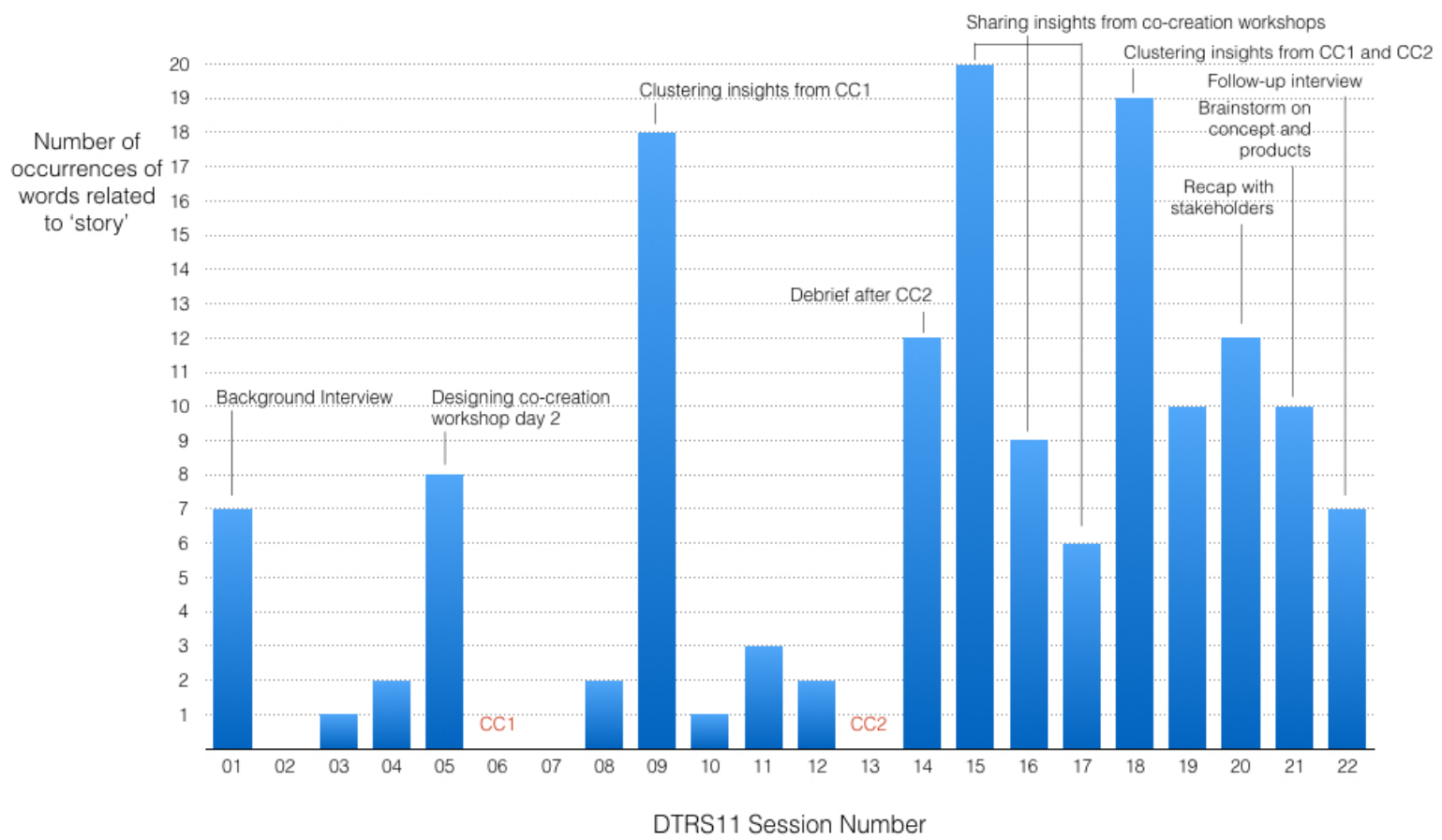

Figure 2. Number of occurrences of words related to 'story' in the DTRS11 dataset.

The phrase 'sexy commitment' is coined by Kenny on Line 116 of Session 9, as the group seek out and begin to create a story that combines both the idea of something that is difficult but good (i.e. 'commitment'), with the idea of something that is more indulgent (i.e. 'sexy'). In the following excerpt Ewan begins by outlining the need for a 'base story' (Line 110) that acknowledges this complexity, a story that is eventually summarised by Kenny's hybrid term:

110 E It is a more complex thing, it is an eco-system of story, but we need a base story. It's just, I think just having this as one part of the story and having kind of the 'car-take responsibility of me' story, those need to go together [...] the whole thing around the me-time and stuff is an important part, but we just, as Kenny is saying, it is almost exhausted...

$111 \mathrm{~K}$ Yeah, but I also agree that it might be really interesting for accessories...

113 A Exactly, because it's exhausted within the rest of the company. Or, not exhausted because it's going on right now so it is super relevant...

$114 \quad \mathrm{~K} \quad$ Yeah, but I also think it's not necessarily, at least for me it's not super sexy. I think it's very easy, it goes in the practical way, that it's gonna solve some very...

115 E Yeah yeah, calendars, and alarm clocks and like, whatever...

$116 \mathrm{~K}$ And maybe that's alright, but then we need to maybe spice it with the sexy commitment (laughs)... 
118 K No not sexy commitment, but with the global awareness responsibility...

119 A And the story around that 'okay, THE COMPANY actually takes care of you, now you have taken care of everyone else, now it's time for you to be pampered a little bit. This is your time'...

120 AM Yeah...

$121 \mathrm{~K} \quad$ So I think maybe this is more about how we tell the story...

122 A Exactly. And then the products could absolutely live within there...

In effect, Kenny takes what Ewan refers to as part of a 'base story' - commitment to global sustainability - and elects to 'spice it up', to compensate for THE COMPANY's focus on practicality and social conscience not being 'super sexy'. By joining the two apparently contradictory categories, of 'sexy' and 'commitment' and thereby coining the two-word term that frequently recurs in the data, the group subsequently begins to identify what might be associated with the term.

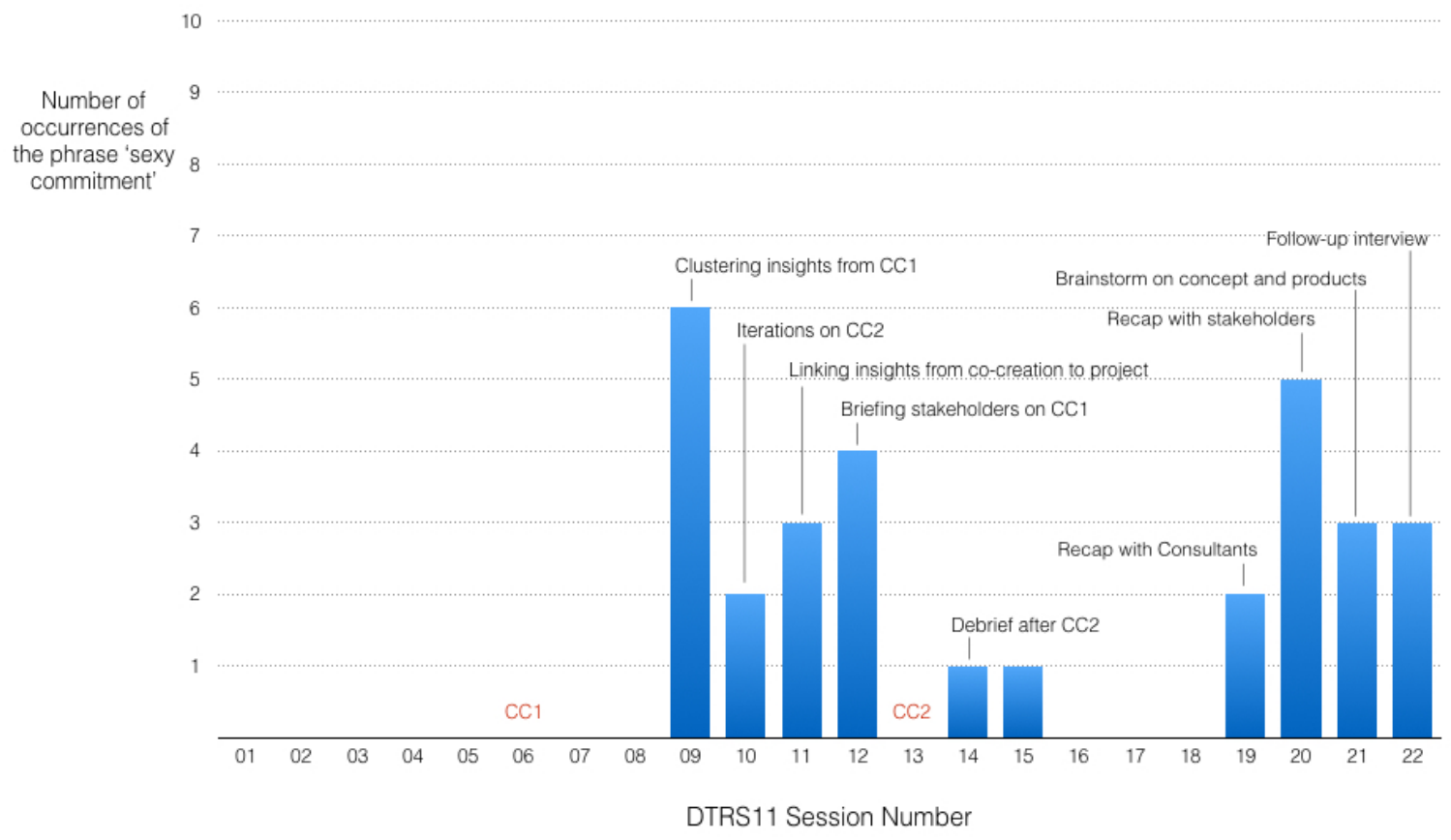

Figure 3. The origin and usage of the phrase 'sexy commitment' in the DTRS11 dataset.

Figure 3 shows that the phrase 'sexy commitment' appears over the course of the dataset a total of 30 times. The pattern of its appearance is interesting as it seems to disappear as a framing idea or structuring story shortly after CC2 only to reappear again in the final 3 
sessions of the dataset (and also in the follow-up interview). This is something that we come to shortly.

The term 'sexy commitment' is important because it encapsulates and frames for the group the shared meaningfulness of an ethical idea about the design project, initially defined as being part of 'the good life'. From the outset, one of the aims of their design process was to identify "the different elements the Active Urbanite needs in his [sic] life to be able to have a good life" (Technical Report, p.19). As we see below quite complex social ideas - politics, war, refugees - are used in stories that develop the meaning of 'sexy commitment', but 'the good life', and especially the idea of 'being good' adds an explicitly moral tone.

In the following excerpt from Session 11, Amanda, an external consultant design researcher, and Ewan discuss the idea that acting for the common good is not something that can easily be talked or 'bragged' about in terms of the self, but can be rewarded in more subtle ways (and it is the idea that 'good' acts deserve reward that they think of as 'sexy'). In the excerpt below Amanda begins by talking about the potential consumer of THE COMPANY car accessory before Ewan tells a story about the 'good' act of a friend of his:

430 AM It's about giving back, right? And that's what we want them to brag about...

431 E Yeah. They're giving back to get something back. Hopefully. But it's the ultimate sacrifice. You give something without asking anything in return. But if you get something in return, it's really good...

432 AM So I'm just thinking about the story where they show the location...

435 E But that's a little disconnected 'cause that is about pure status symbol. Here we want them to help out at the school and yeah okay, so you show the location of that school in a photo. Like I have a good friend in Norway, and she's super first world, super Norwegian, tons of money, she quit her job to go- she was between jobs, and then she went down to: Greece, to help the refugees coming inland, which is a good thing to do. But she was, several times a day, posting images of her holding babies, saving babies. Why did she do it? I don't know. Did she do the whole thing to promote herself? It was done in a very understated way...

AM Okay. So it's about finding that connection, right? that connection point...

Here we see how Ewan develops the concept of 'sexy commitment' with a story about a 'good friend' of his who 'quit her job' to go to Greece and help refugees arriving (Line 435)2. 
Although describing these actions as 'a good thing' he then goes on to question her motivation for doing this because of the images she posted to social media with her 'holding babies, saving babies' (Line 435). He raises the possibility that his friend might have done this as an act of self-promotion rather than a self-less act of aid. Amanda understands that Ewan is sketching a polarity between the self that seeks reward, on the one hand, and the selfless, that seeks only to do good, on the other. She sums up Ewan's story by implying that 'sexy commitment', and the products that might follow from this 'base story', are about finding what she calls the 'connection point' between the two poles (Line 436).

The term 'sexy commitment' thus emerges as a shared story for the group, becoming part of their vocabulary for talking about the psychological and cultural landscape for a future product. However, in the three sessions following CC2 (where 'sexy commitment' only appears on a Post-it note), the term disappears altogether. It is only in Session 19 that it reappears, with the shared meaning evident when Ewan explains an unresolved aspect of the product as "sexy commitment lives a little bit here" (Line 3). The phrase begins to reappear again for the group in the final three sessions of the dataset. In Session 20, the final session of the trip to China, Ewan summarises what the group have done for Tiffany and Hans (executives for THE COMPANY). Here 'sexy commitment' is one of the themes Ewan talks about, in effect telling a story about a story:

12 E And then this one, which is called "sexy commitment", and we have had this from the very first week, actually, where "sexy" is kind of what you get back, and "commitment" is what you sacrifice...

Neither Tiffany nor Hans ever use the term 'sexy commitment', perhaps because they have a more product-focussed role in THE COMPANY and perhaps also because they were not present when the story emerged as meaningful within the group. Indeed it is a phrase that perhaps represents the distance between Ewan's more conceptual 'co-design' approach and the more conventional product development approach of Tiffany and Hans that we describe in the following section, a distance that is further reinforced by the late arrival of Tiffany and Hans in China (missing several activities in which the designers participated as a group). In Session 20 it is only Ewan and Kenny who use the term.

\section{THE COMPANY Story}


While the designers plan a co-creation workshop that will be friendly, non-hierarchical, and fun for the participants (potential consumers of the products) the aim of the workshop is to accomplish particular tasks to suit the needs of THE COMPANY. The social and cultural values of care and equality may fit well within the designers' education, and expectations of themselves as people, but the design team are also required to assist company profitability through developing new products that will engage consumers and maintain brand success. In Background Interview 2 (conducted with Ewan when the project was finished) Ewan tells the story of how the design project was first initiated through a 'random' meeting between two directors who pithily concluded: "we have low take rates in China, we need to do something about it" (Line 65). Corporate needs thus underpin the same workshop shaped by the designers as egalitarian. Throughout their activities and interactions, the designers have to manage the values associated with the category 'being corporate' as well as those associated with the category of 'egalitarian sociability'. In effect, the designers' own everyday practices involves a tension that is similar to the one they attempt to encompass through the term 'sexy commitment'.

It is perhaps no surprise that the team's performance of these more explicitly competitive corporate values - expressed through phrases such as 'take rates', 'alignment', and 'sales peak' - occurs in settings where the group is talking with stakeholders from THE COMPANY. In the following sequences of talk from Session 20, below, Ewan first begins to outline the general areas that the design team have explored within the co-creation workshops, with some discussion of what the resulting outcomes might be - for example, outcomes such as an allegiance to the 'sexy commitment' story. A company employee and stakeholder, Tiffany, is terse in her response to Ewan (line 10), in which she questions, and implies a critique of, the design team's process in relation to THE COMPANY's financial interests (i.e. 'risks' and 'benefits'). Ewan's response is itself a question that challenges her budget-centred focus.

$\begin{array}{lll}9 & \text { E } & \text { What are the risks of doing this? What are the benefits and so on? } \\ 10 & \text { T } & \text { And do we have the budget for it? } \\ 11 & \text { E } & \text { Yeah [laughter] or can we afford not to have the budget for it? }\end{array}$


Soon after this exchange, however, Ewan's talk (Line 21 below) indicates his awareness of THE COMPANY's product-focused bottom line, as he references the creation of 'heroproducts' that help to 'conquer' a market to ensure THE COMPANY's growth. Further, he signals acceptance of and affiliation with their position, given his use of the term 'we' to imply both him personally and THE COMPANY.

21 E This is why we should have one or two hero-products that appeal to these people $[\ldots]$ how can we focus here to conquer these people? [...] We want to be in conquest, we want to grow...

His shift in talk towards directly referencing corporate needs helps to also shift the conceptual frame of the meeting. A recognition of THE COMPANY's needs is further taken up as Ewan reiterates the requirement to 'conquest with an accessory' (Line 29, below).

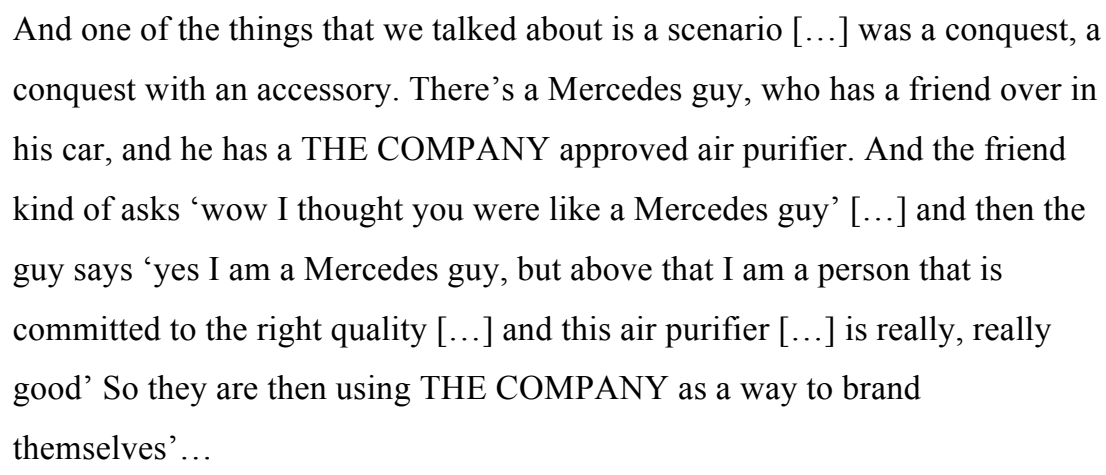

It is significant for our analysis that Ewan tells a story of how such a conquest might happen. Here Ewan talks about a potential consumer; someone who might typically be categorised as a 'Mercedes guy'. Ewan depicts this person showing off his air purifier, which is a product accessory not from Mercedes but from THE COMPANY. The point of Ewan's brief narrative - a story told in the voice of the friend who is supposedly talking to the 'Mercedes guy' - is that this 'Mercedes guy' has associated himself with the 'good' qualities of THE COMPANY (i.e. 'committed to the right quality') to the point that the 'Mercedes guy' has re-categorised himself, i.e. branded himself, through the use of THE COMPANY's products, and accordingly, with their espoused values.

While recognising that a business has to 'conquest' a market if it is to succeed, the telling of the story illustrates, through a set of imagined particulars, the mechanism of success - how 
buying an accessory "makes people able to sample the THE COMPANY's values, without making the full commitment of having a car" (Line 29). This brief story serves to negotiate and nuance the business-oriented, 'take rate' values of THE COMPANY with the socialresponsibility values of the designers, decreasing what we might term a value tension that seeks to balance two different value orientations. Both the stakeholders and the designers can interpret the story within their dominant value system.

We can see how the story concerning the nature of the consumers' character shifts its value focus towards a business orientation in Session 21. Here, in the final session of the DTRS data and located back in Scandinavia again, the designers talk with colleagues to help them come up with ideas for 'real' products. In the following extract from that meeting, Abby outlines for her colleagues an analysis of what the workshop participants, as potential product consumers, said they value the most in their lives. Abby's comments reframe the participants' actual multifaceted, complex ruminations on what they spoke of as 'the good life' and 'health' into a brief and rather simplistic depiction that emphasises individualism and acquisitiveness:

49 A They are super opportunistic, so [they want to] break free of their parents' way of living. They really go for every opportunity to earn extra money, to be able to differentiate themselves or build up their living standards...

Later, in the same brainstorming session, Kenny reiterates the importance of THE COMPANY's product to the consumer's perceived social status (line 99). In Kenny's description, the product acts to identify knowledgeable and sophisticated consumers to each other, and so the product becomes more than an individual's fulfilled desire, it also becomes an agent of social capital.

I think also the recognition that you get is also a confirmation that you are climbing up the social ladder because in order for them to recognise you they must have the same level of sophistication and intellect to understand the values that you have, so when they recognise you it is a confirmation that you are actually climbing up the social ladder at the same time...

These brief imaginations of consumer behaviour widen THE COMPANY's association with an underpinning narrative that frames perceptions and actions: not only are the potential 
consumer's choices associated with the product's demonstration of 'sexy commitment', they are also about the more overt performance of 'climbing up the social ladder'. The designers' construction of the 'sexy commitment' story has not only served to hold value tension for the consumer (between 'sexiness' and 'commitment') but also for the designers themselves as they present a more acceptable business-centred logic to other employees of THE COMPANY whose task it is to come up with specific products.

The co-design process of the dataset poses the challenge of transposing the knowledge gained from the co-creation workshops into viable products that will satisfy a company's needs. The original design team are hopeful that they can succeed, but a range of actors (e.g. Tiffany and Hans) beyond the design team impact upon the realisation of the team's original aims - which were both to create concepts (if not actual products) and also to 'showcase' how co-creation's 'user involvement' approach could "work as change agents for the organisation" (Background Interview 2, Line 95). In this sense Ewan, as the chief narrator of the process, is telling (or maybe selling) a story of organisational change; of how a well-executed example of cocreation for a car accessory product can begin to reframe THE COMPANY's design process in ways that will not only impact the design of vehicle accessories, but also transform the way that the cars themselves are designed. This shift in design thinking - from the shaping of products to the shaping of stories - is what drives Ewan throughout the process and which makes an analysis of what the stories that emerge represent interesting.

\section{Stories and Value Tension}

We've shown how the phrase 'sexy commitment' expresses contrasting values: commitment and duty on the one hand, indulgence and selfishness on the other. We showed how the phrase is taken up and used by the designers through subsequent sessions in the dataset as a means to categorise and evaluate activity and ideas. Sexy commitment is not the only phrase that emerges as a useful framing device for design activity in the data, but its consistent development and deployment marks it out as a significant contributor to the co-design process.

The story that the term 'sexy commitment' represents goes some way in meeting the requirement for a 'region relevant story' in the project brief, even though the term and the story itself arises out of a controlled set of conditions; i.e. the design of the co-creation 
workshops. By carefully setting the criteria for the workshop participants then prescribing the activities of the workshops to achieve particular social ends we saw how the "sexy commitment' story underpins a more fundamental transmission of cultural values. In effect, the phrase is itself an expression of the value tension that can be seen to result from the constructions and perceptions of difference between (crudely put) the more egalitarian values that are often associated with Scandinavian design and the more hierarchical values of contemporary, urban, youth-oriented Chinese culture.

The business and commercial aspects of THE COMPANY sets up a different value tension, in this case between the 'socially responsible' team of designers involved in the co-creation process and THE COMPANY stakeholders (Tiffany and Hans), who are familiar with a more conventional product development and business environment: one that is focused on 'conquest', budgets, production plans, and dealerships, rather than on, for example, the use of animal avatars to reduce hierarchies between strangers who are meeting for the first time. The 'sexy commitment' and 'Mercedes guy' stories, as other effective stories do, allow two value conditions to co-exist.

Throughout the DTRS11 data, each designer indicates an ongoing awareness of the cultural and personal characteristics of the workshop participants, both initially when they are imagining what they might be like, and later, when they reflect on the words, actions, and other activities of the workshop participants. This awareness seems particularly to be the case for Ewan, who engages in an extensive discussion of the conflicts between the collective and the individual in Chinese society in Session 21 (line 2). However all members of the design team adeptly translate nuanced social information into simple phrases that frame their understanding in ways that are relevant to their corporate colleagues. The designers skillfully notice, create, and tell stories that are underpinned by contrasting norms and values; practices illustrated in Figure 4, where the two stories summarised by the terms 'sexy commitment' and 'Mercedes guy' allow contrasts to coexist. 


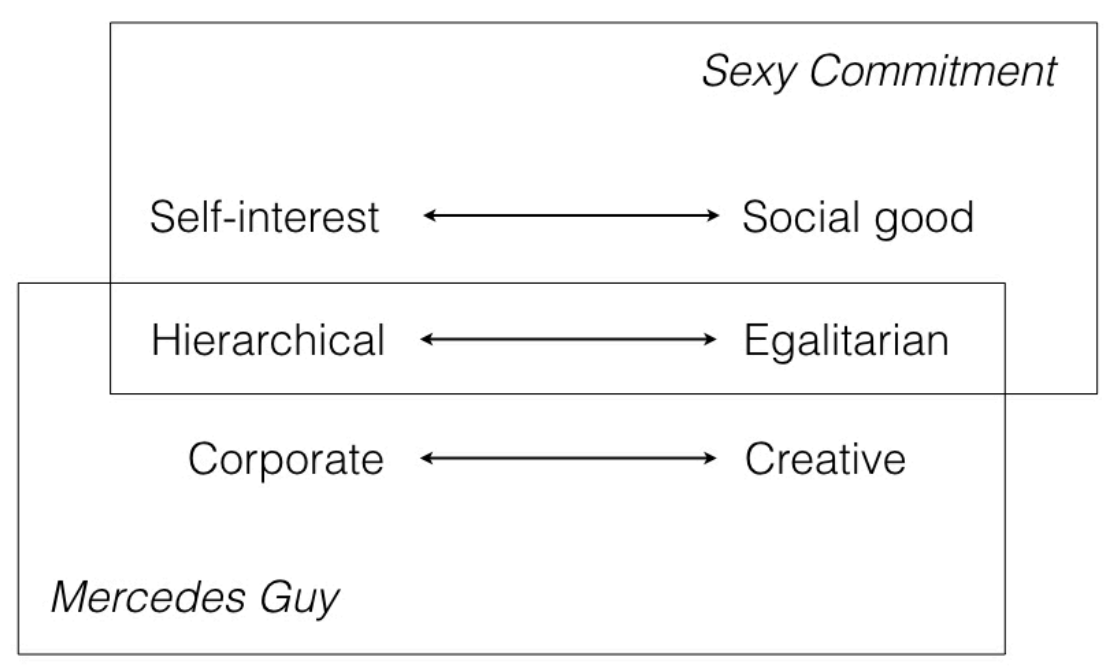

Figure 4. Illustration of the different value tensions that the two stories 'sexy commitment' and 'Mercedes guy' hold and share.

\section{Summary and Conclusions}

The design process, in the way that it bridges past and future, is a fertile ground for storytelling but the co-design process that the DTRS11 data represents is particularly rich in the interleaving of stories in many forms. The linguistic and textual expertise of the designers is notable here and contrasts with other accounts of design thinking expertise that focus around the activity of prototyping (Gerber \& Carroll 2012). Although the co-designing process we've looked at was organised around discussion and conversation, it is nevertheless striking that what was generated was almost entirely text based, with participants and designers writing on Post-it notes, flip charts and white boards. The structures of categorisation and organisation that such tools afford are central to the production of written and spoken text as the design process develops.

This kind of design thinking appears less about dealing with uncertainty through the construction of prototypes, as Gerber and Carroll (2012) find, and more about dealing with tension through the construction of stories. In considering how the psychological tension produced from contradiction in creative processes is handled, Paletz et al (2017) draw a distinction between two types of dialectical thinking. The first type, 'Hegelian dialectic', aims at synthesis and integration, resolving contradictions through an iterative 'back and forth' process. This is perhaps similar to Schön's reflection in action (1983) and the process of 
prototyping identified by Gerber and Carroll (2012) above. The second type, 'naïve dialectical thinking', posits that 'because aspects of reality are constantly changing, oppositions also coexist and are ever-present'. These contradictions need not be resolved, they write, indeed concepts can only be understood when they stand in opposition to other concepts. This is more closely aligned to our observations in this paper. The fluidity, ambiguities and contradictions around values, particularly in the early stages of cross-cultural co-design processes, are managed through the creation of stories, and those stories allow contrasting values to coexist, whilst moving the design process forwards.

Our aim in this paper has been to draw attention to some of the actions and interactions of participants, and to explore some moments in the overall design process that appeared particularly meaningful to the participants. This attention to the specific situations in which the designers found themselves and through which they enacted design, means that our work is underpinned by an ethnomethodological perspective that attends to how people themselves collaborate to create meaningful and accountable social action (Garfinkel 1991, von Lehn, 2014). We did not seek to test a particular theory, nor to begin with a specific or even generalised theory into which the analysis of data could be channeled or sited. Instead our paper is influenced by and aligned with those works that orient towards careful descriptions of specific situations of social action (Latour 1999, Suchman 2007, Yaneva 2003) in order to consider the complexity of what is going on, through terms that would likely be recognisable to the participants themselves.

We have discussed how stories, based in the everyday conversations through which design is practiced in co-design contexts, construct and hold value tensions that help to anchor the design process. The uniqueness and richness of the cross-cultural data, involving as it does both Scandinavian and Chinese participants, and both creative designers and more businessoriented corporation employees, has allowed us to explore this idea in some detail. The stories we have identified, and we think also others in these data, have a bipolar structure that maintains a level of complexity but packages it in a simple and understandable way. Sometimes these stories come directly from someone's experience - Ewan's bible story, for example - but the stories that have particular resonance in the data, like that represented by the phrase 'sexy commitment', are flexible enough to bridge 'past particulars' - i.e. experiences and behaviours that the co-design process reveals - with 'imagined particulars' i.e. stories that place specific actors, objects and relations into an future-oriented context. A 
story in this sense provides a dynamic structure through which values can be framed and categorised, and through which design-oriented arguments can be presented.

Notes

[1] Interestingly, in the light of our opening sentence, Dong and Macdonald (2017) refer to the idea of sexy commitment as a 'frame' in the Schön (1983) sense. Though it can be viewed as such, in our view the use of the term in describing and allowing multiple narratives gives it a complexity that warrants the more dynamic term 'story'.

[2] The 'wealthy-women-assisting-refugees' story is also analysed by Dong and Macdonald (2017) in terms of the semantics of 'status'.

Acknowledgements

We would like to thank Bo Christensen, Linden Ball, and all at the Copenhagen Business School for collecting and editing the DTRS11 dataset that this paper is based on.

References

Ball, L., Christensen, B. \& Halskov, K. (2017). Analysing design thinking: Studies of crosscultural co-creation. Leiden: CRC Press/Taylor \& Francis.

Beckman, S. \& Barry, M. (2009). Design and innovation through storytelling. International Journal of Innovation Science, 1(3), 151-160.

Bamberg, M. \& Georgakopoulou, A. (2008). Small stories as a new perspective in narrative and identity analysis. Text \& Talk, 28(3), 377-396.

Beckman, S. \& M. Barry (2009) Design and innovation through storytelling. International Journal of Innovation Science, 1(3), 151-160. 
Booker, C. (2004). The seven basic plots: Why we tell stories. A\&C Black.

Cross, N., Dorst, K., \& Christiaans, H. (Eds.). (1996). Analysing design activity. London: Wiley.

Dong, A. \& Macdonald, E. (2017). From observations to insights: The hilly road to value creation. In B. Christensen, L. Ball, \& K. Halskov, (Eds.) Analysing design thinking: Studies of cross-cultural co-creation, (pp. 465-482). Leiden: CRC Press/Taylor \& Francis.

Dorst, K. (2015). Frame innovation: Create new thinking by design. Cambridge Mass: MIT Press.

Ensink, T. \& C. Sauer (2003). Framing and perspectivising in discourse. Philadelphia: John Benjamins.

Garfinkel, H. (1991). Studies in ethnomethodology. London: Polity Press.

Gerber, E. \& Carroll, M. (2011). The psychological experience of prototyping. Design Studies, 33(1), 64-84.

Goffman, E. (1981). Forms of talk. University of Pennsylvania Press.

Housley, W. \& Fitzgerald, R. (2002). The reconsidered model of membership categorisation analysis. Qualitative Research, 2, 59-83.

Housley, W. \& Fitzgerald, R. (2009). Membership categorisation, culture and norms in action. Discourse \& Society, 20(3), 345-362.

Jornet, A. \& Roth, W-M (2017). Design \{thinking | communicating\}: A sociogenetic approach to reflective practice in collaborative design. In B. Christensen, L. Ball, \& K. Halskov, (Eds.) Analysing design thinking: Studies of cross-cultural co-creation, (pp. 465482). Leiden: CRC Press/Taylor \& Francis. 
Latour, B. (1999). Circulating reference: Sampling the soil in the Amazon forest. In B. Latour. Pandora's hope: Essays on the reality of science studies (pp. 24-79). Harvard University Press.

Lloyd, P. (2000). Storytelling and the development of discourse in the engineering design process. Design Studies, 21(4), 357-373.

Lloyd, P. \& Oak, A. (2016). Houses of straw: Grand Designs and the presentation of architectural design on television. Design and Culture, 8(2), 155-180.

McCloskey, D. (1990). Storytelling in economics. In C. Nash (Ed.) Narrative in culture: The uses of storytelling in the sciences, philosophy, and literature (pp. 5-22). London: Routledge.

Murphy, K. (2015). Swedish design: An ethnography. Ithaca: Cornell University Press.

Oak, A. (2013b). Narratives in practice: The small and big stories of design. In L. Sandino \& M. Partington (Eds.) Oral history in the visual arts (pp. 181-188). London: Bloomsbury.

Paletz, S., Bogue, K., Miron-Spektor, E., \& Spencer-Rodgers (2015). Dialectical thinking and creativity from many perspectives: Contradiction and tension. In J. Spencer-Rodgers \& K. Peng (Eds.) Psychological and cultural foundations of dialectical thinking. Oxford University Press.

Paton, B., \& Dorst, K. (2011). Briefing and reframing: A situated practice. Design Studies, 32(6), 573-587.

Prahalad, C. \& Ramaswamy, V. (2004). Co-creation experiences: The next practice in value creation. Journal of Interactive Marketing, 18(3), 5-14.

Sacks, H. (1972). On the analyzability of stories by children. In J. Gumperz \& D. Hymes (Eds.) Directions in sociolinguistics: The ethnography of communication (pp. 325-345). New York: Rinehart \& Winston.

Schön, D. (1983). The Reflective Practitioner. New York: Basic Books. 
Sanders, E. \& Stappers, P. (2008). Co-creation and the new landscapes of design. CoDesign, $4(1), 5-18$.

Stokoe, E. (2012) Moving forward with membership categorisation analysis: Methods for systematic analysis. Discourse Studies, 14(3), 277-303.

Suchman, L. (2007). Human-Machine Reconfigurations: Plans and Situated Actions. Cambridge University Press.

Umney, D., Lloyd, P., \& Potter, S. (2014). Political debate as design process: A frame analysis. In Lim, Y-K., Niedderer, K., Redström, J., Stolterman, E., \& Valtonen, A. (Eds.) Proceedings of DRS2014: Design's big debates, Umea, Sweden, 16-19 June.

Umney, D. \& Lloyd, P. (2018). Designing frames: The use precedents in parliamentary debate. Design Studies, 54, 201-218.

von Lehn, D. (2014). Harold Garfinkel: The creation and development of ethnomethodology. London: Routledge.

Yaneva, A. (2003). Chalk steps on the museum floor: The 'pulses' of objects in an art installation. Journal of Material Culture, 8(2), 169-188. 